\title{
INFLUENCE OF CRYOROLLING ON PROPERTIES OF L-PBF 316L STAINLESS STEEL TESTED AT 298K AND 77K
}

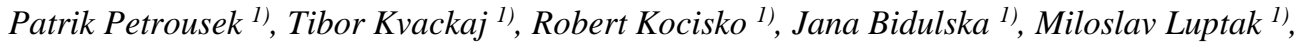 \\ Diego Manfredi ${ }^{2)}$, Marco Actis Grande ${ }^{2)}$, Robert Bidulsky ${ }^{3)^{*}}$ \\ 1) Technical University of Kosice, Faculty of Metallurgy, Materials and Recycling, Dpt. of \\ Plastic Deformation and Process Simulation, Letna 9, 040 01, Slovakia \\ 2) Politecnico di Torino, Department of Applied Science and Technology, Corso Duca degli \\ Abruzzi, 2410129 Torino, Italy \\ 3) Authorised representative for innovation and technological transfer, Košice Self-Governing \\ Region, Namestie Maratonu mieru 1, 04266 Kosice, Slovakia
}

Received: 08.11.2019

Accepted: 10.12.2019

${ }^{*}$ Corresponding author: e-mail: robert.bidulsky@arr.sk, Tel.:+421 05568228 22, Presidents plenipotentiary for innovation and technological transfer, Košice Self-Governing Region, Namestie Maratonu mieru 1, 04266 Kosice, Slovakia

\begin{abstract}
The goal of the present work is to evaluate mechanical properties and to analyse the microstructure of 316L stainless steel produced by Laser Powder Bed Fusion (L-PBF) follow by rolling with different thickness reduction under ambient and cryogenic conditions. The samples before rolling were heat treated. The static tensile test was realized at ambient and cryogenic $(77 \mathrm{~K})$ conditions. The L-PBF powder metal production technology approved that is a key technology in the additive manufacturing (AM) area, especially for metal powder materials. Mechanical properties tested at $298 \mathrm{~K}$ and $77 \mathrm{~K}$ shows that the application of various thermo-deformation rolling conditions increases of strength properties. Achieved mechanical properties are comparable to conventional bulk materials. The strength properties after the rolling under ambient and cryogenic conditions were significantly increased.
\end{abstract}

Keywords: stainless steel, laser powder bed fusion, cryogenic conditions, mechanical properties, cryorolling

\section{Introduction}

Additive manufacturing (AM) is a technology that has wide possibilities for producing materials and products of common as well as extraordinary properties through powder metallurgy (PM). PM products are exceptional due to their features but also because their price is significantly lower than products produced by other technologies [1-6]. The biggest benefits are: possibility to produce components of very complicated shapes, use of extremely hard and solid materials, production of composite materials and last but not least, high material savings. AM technologies can achieve up to $90-95 \%$ of material savings. With the help of progressive technologies, it is possible to recycle the used powder material and increase the percentage of its utilization up to $100 \%$ [7-12].

Laser Powder Bed Fusion (L-PBF) technology is particularly important in PM. With a laser beam melt the powder particles in a precisely defined field and liquid phase can be achieved in a very 
short time. During the interaction between the surface of the powder layer and the laser, the powder particles are rapidly melted [13-15]. This process will rapidly melt the powder particles and rapidly transfer to solid form without any direct addition of other material elements to modify the chemical composition [16-18]. Due to the relatively low penetration of the liquid phase to a depth (approximately $10-1000 \mu \mathrm{m}$ ), very high cooling rates of $10^{3}$ to $10^{6} \mathrm{~K} \cdot \mathrm{s}^{-1}$ are achieved [19]. High internal thermal stresses created in the material because of the high cooling rates must be removed before further processing. [19-22].

Nowadays, it is possible to produce products using L-PBF technology with mechanical properties at the level of conventionally produced materials. Conventionally produced 316L stainless steel, which is intended for the energy sector, have yield strength values of $500 \mathrm{MPa}[23,24]$. The steel grade $316 \mathrm{~L}$ is successfully applicable for working under cryogenic conditions, for example as the construction parts at fusion reactor. For application at fusion reactor nowadays is requirement on the yield strength must reach value $\mathrm{R}_{\mathrm{P} 0,2} \geq 1200 \mathrm{MPa}$. [25-27].

The properties of $316 \mathrm{~L}$ stainless steel can be influenced by thermo-mechanically controlled processing under cryogenic conditions, and thus strength properties exceeding $\mathrm{R}_{\mathrm{m}} \approx 1600 \mathrm{MPa}$ can be achieved [3]. With increasing dislocation density, dislocation movement and stress concentration are inhibited. This causes the plastic deformation mechanism to be triggered by mechanical twinning. With a further increase deformation, it can be assumed that grain refinement will occur until a grain size structure of the order of nanometres can be achieved. The mechanical properties of materials it is possible to increase by forming under cryogenic conditions [27-29]. In this paper are investigating the mechanical properties of samples from 316L PM stainless steel prepared by L-PBF and heat treatment which were subsequently rolled at ambient and cryogenic temperatures. The rolled samples were tested under ambient and cryogenic conditions.

\section{Experimental material and methods}

Commercially produced material EOS Stainless Steel 316L with chemical composition $18 \% \mathrm{Cr}$, $14,5 \% \mathrm{Ni}, 2,5 \% \mathrm{Mo}$, and $0,5 \% \mathrm{Si}$ was used in the study. The particles of 316L powder were analysed using a FESEM Zeiss Supra 40 microscope. The particles have mostly an ideal spherical shape with particle sizes in range $<10 ; 60>[\mu \mathrm{m}]$ and average particle size was $33 \mu \mathrm{m}$. Sieve analysis was performed following ASTM B 214-07.

The samples produced for the static tensile test were heat treated. The samples before rolling were annealed by solution annealing at $1050^{\circ} \mathrm{C} / 60 \mathrm{~min}$, followed by artificial aging at $700{ }^{\circ} \mathrm{C} / 3000$ min. The samples were marked as HT2.

\section{L-PBF technology}

The samples were made using L-PBF technology on an EOS M280 Dual Mode (EOS GmbH, Krailling / Munich, Germany). The EOS M280 is equipped with a 200W Yb fiber laser. The samples were produced in an argon atmosphere with a $20 \mu \mathrm{m}$ layer thickness and a meander scanning strategy. Table 1 shows the bases of the manufacturing process parameters, where $\mathrm{P}$ is the laser power, $\mathrm{S}_{\mathrm{s}}$ is the scanning speed, $\mathrm{h}_{\mathrm{d}}$ is the hatching distance of individual laser paths, and $S_{1}$ is the length of the welding strip.

Table 1 Parameters optimized for the fabrication of dense samples in SS 316L through an EOS M280 machine

\begin{tabular}{|c|c|c|c|}
\hline $\mathbf{P}[\mathbf{W}]$ & $\mathbf{S}_{\mathbf{s}}\left[\mathbf{m m}_{\mathbf{.}} \mathbf{s}^{-1}\right]$ & $\mathbf{h}_{\mathbf{d}}[\mathbf{m m}]$ & $\mathbf{S}_{\mathbf{l}}[\mathbf{m m}]$ \\
\hline 195 & 800 & 0,09 & 800 \\
\hline
\end{tabular}




\section{Static tensile test}

The static tensile test at $298 \mathrm{~K}$ and $77 \mathrm{~K}$ was performed on the TINIUS OLSEN H300KU with Horizon software. Under both temperature conditions, the crosshead movement speed of 0.3 $\mathrm{mm} . \mathrm{s}^{-1}$ was chosen, which corresponds to a strain rate of $0.0023 \mathrm{~s}^{-1}$ following STN EN ISO 68922 .

\section{Results and discussion}

\section{Mechanical properties}

The values of mechanical properties after rolling under different rolling conditions can be summarized in the Fig. 1 and Fig. 2. In Fig. 1 the mechanical properties of samples rolled under AT (ambient temperature) and CT (cryogenic temperature) follow by static tensile tests performed at ambient temperature $\mathrm{T}_{\text {test }}=298 \mathrm{~K}$. For deformations $\varepsilon=71 \%$ and $86 \%$ were $\mathrm{R}_{\mathrm{p} 0,2, \mathrm{AT}} \in<1017$; $1070>[\mathrm{MPa}] ; \mathrm{R}_{\mathrm{m}, \mathrm{AT}}\langle 1165 ; 1300\rangle[\mathrm{MPa}]$ and $\mathrm{A}_{\mathrm{t}, \mathrm{AT}}\langle 5 ; 6\rangle$ [\%]. After CT rolling with $\varepsilon=40 \%$, strength properties were achieved at the level of specimens rolled at deformations of $\varepsilon=71 \%$ and $86 \%$. The total elongation $A_{t}$ value for samples rolled with deformations above $40 \%$ was almost constant $5-6 \%$. When rolling in AT and CT at selected deformations higher than $40 \%$, the strength properties increased three-fold compared to the initial state. A significant increase in strength properties resulted in a significant decrease in $\mathrm{A}_{\mathrm{t}}$.

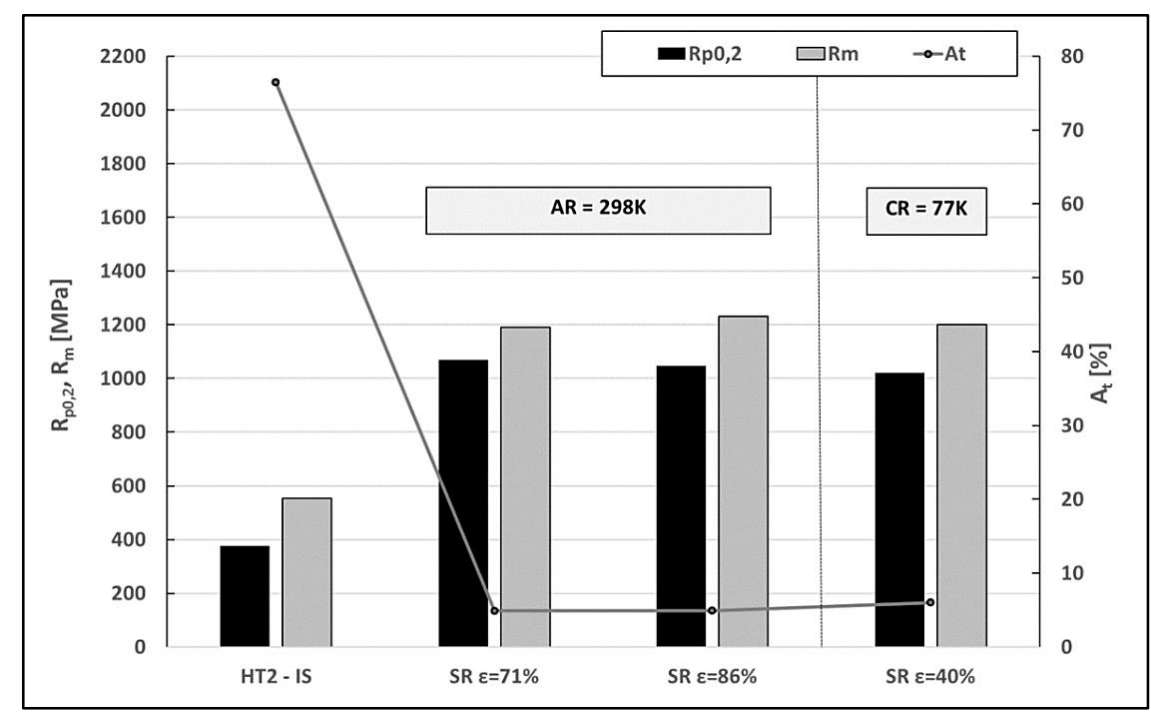

Fig. 1 Mechanical properties of the samples rolled under AT and CT conditions and tested by static tensile testing at $298 \mathrm{~K}$

The Fig. 2 depicts that the static tensile test at $T_{\text {test }}=77 \mathrm{~K}$ showed a further significant increase in strength properties. The increment $\mathrm{R}_{\mathrm{p} 0.2}$ after symmetric rolling at $\mathrm{CT}\left(\mathrm{SR}_{\mathrm{CT}}\right)$ is almost the same as $\mathrm{SR}_{\mathrm{AT}}$ at twice the deformation.

The measured values indicate that even at half deformation in CT conditions it is possible to achieve strength properties at the level of materials rolled under AT conditions. The value of $A_{t}$ was approximately the same for the measured conditions after rolling and a small increase was observed after the static tensile test under conditions $\mathrm{T}_{\text {test }}=77 \mathrm{~K}$. 


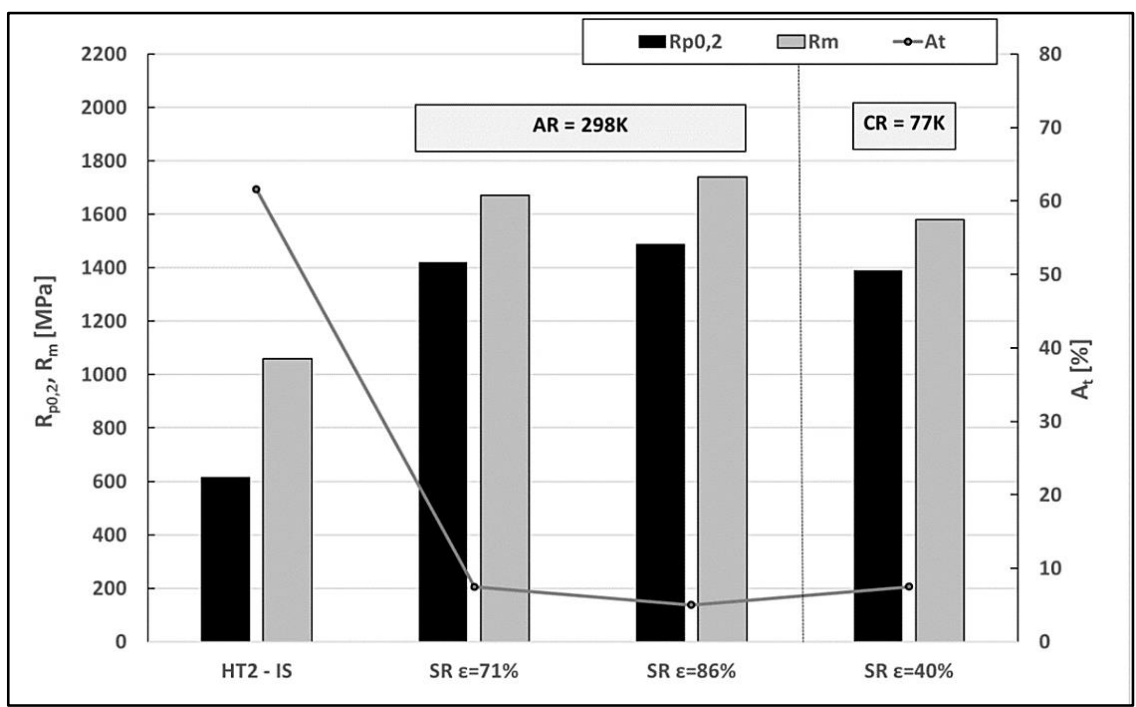

Fig. 2 Mechanical properties of the samples rolled under AT and CT conditions and tested by static tensile testing at $77 \mathrm{~K}$

Based on these results, it can be concluded that after the deformation conditions selected, the maximum possible mechanical properties have been achieved and further enhancement of the mechanical properties must be associated with the modification of the structure.

Based on the analysis of mechanical properties under various conditions of thermal and deformation treatment of the material, it is possible to compare the results with the values of recommended mechanical properties of the material 316L according to works [30-32] for fusion reactor. The initial state had about $30 \%$ higher $A_{t}$ values as compared to conventionally rolled material $A_{t} \leq 42 \%[31,32]$. The initial state tested at $T_{t}=77 \mathrm{~K}$ retained a high $A_{t}$ value with almost doubling the strength properties. After rolling of the HT2 state, a significant increase in $\mathrm{R}_{\mathrm{p} 0.2}$ was achieved. A comparison of the mechanical properties of rolled bulk materials and materials produced by L-PBF technology shows that L-PBF technology can produce materials with properties close to the level of rolled materials.

\section{Microstructure}

The microstructure of Fig. 3a shows that after the chosen solution annealing and artificial aging, grains were recrystallized with the exclusion of oxide and carbide particles, which are mainly visible in SEM images (Fig. 3b). The average grain size after the solution annealing and artificial aging was $35 \mu \mathrm{m}$. On the microstructures is visible a quasi polyedric structure with different sized austenitic grains. At the grain boundaries, precipitation of oxidic and carbide particles can be observed. STEM EDS identified two types of precipitates in grains and two types of precipitates contouring the high grain boundaries. Large precipitates ( $>200 \mathrm{~nm}$ ) inside the grains and along the grain boundaries are of the $\left(\mathrm{Mn}, \mathrm{Cr}_{2}\right) \mathrm{O}_{4}$ and $\mathrm{MnO}_{2}$. Large precipitates lying along the grain boundaries are $\mathrm{Cr}_{23} \mathrm{C}_{6}$ carbides.

The Fig. 4-6 show microstructures of samples rolled under various deformation conditions. It can be seen that with the deformations $\varepsilon=71 \%$ and $86 \%$, the grains were significantly elongated into the rolling direction and significant slip strips were formed. Some grains in the rolling direction were elongated more than $500 \mu \mathrm{m}$. According to the authors [33, 34], $\mathrm{d}_{\gamma, \text { kor }}$ was calculated for 
individual deformation conditions. As the deformation increased, an overall reduction of $\mathrm{d}_{\gamma}$, kor. Samples with $\varepsilon=71 \%$ and $86 \%$ had values $\mathrm{d}_{\gamma, \text { kor }} \in<20 ; 23>[\mu \mathrm{m}]$.

a)

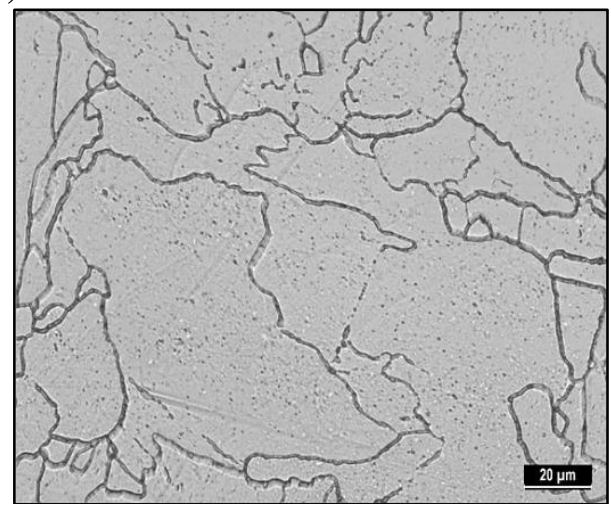

Fig. 3 a) Microstructure of initial state HT2 b)

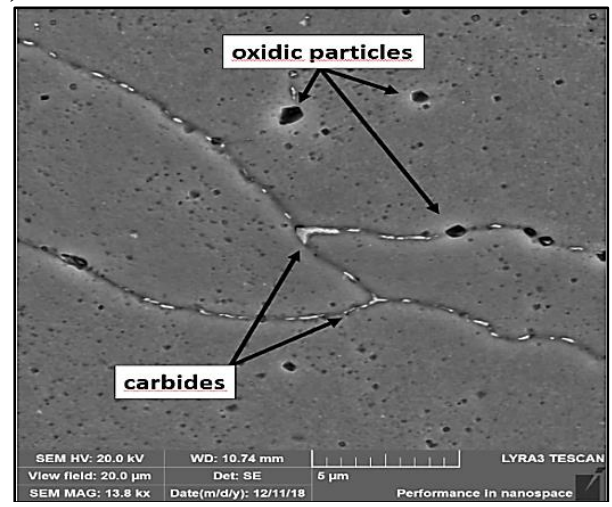

b) SEM microstructure of oxidic and carbidic precipitates

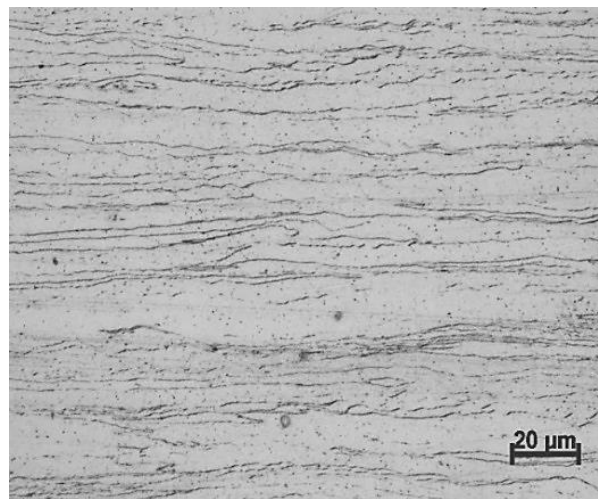

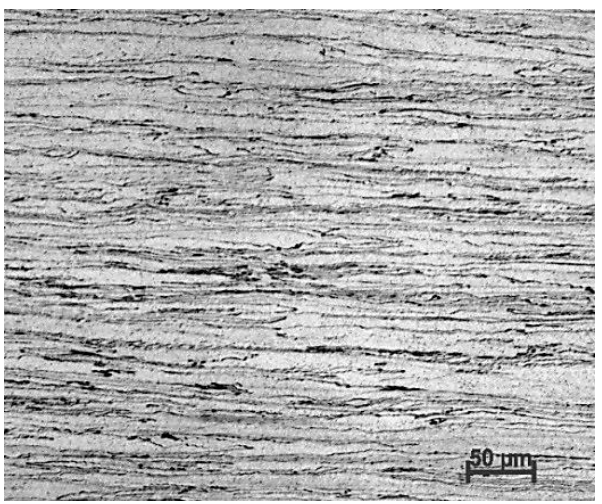

Fig. 4 Microstructure after rolling with $\varepsilon=86 \%$ under ambient temperature
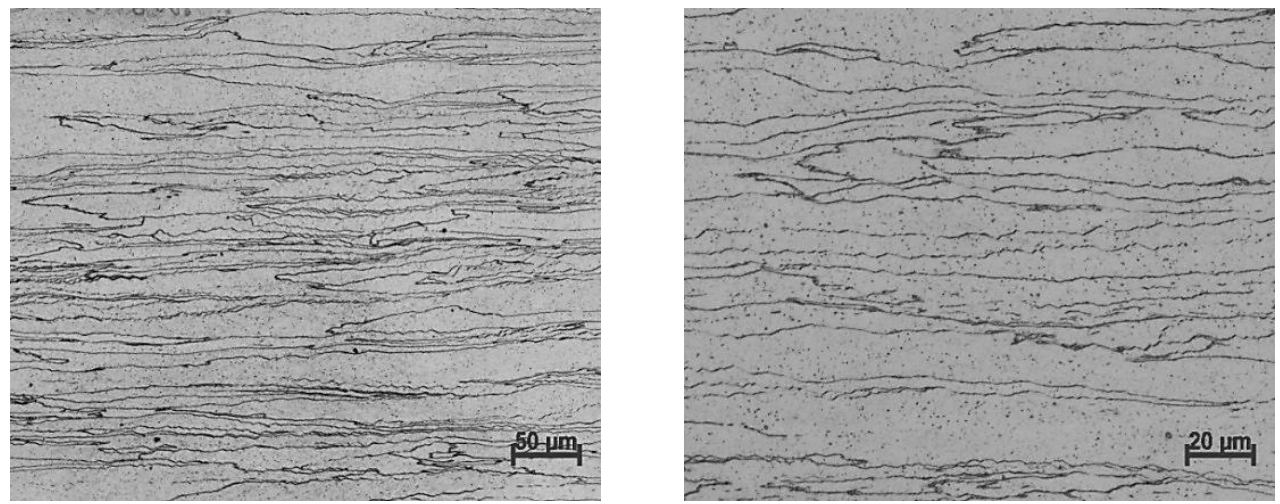

Fig. 5 Microstructure after rolling with $\varepsilon=71 \%$ under ambient temperature 

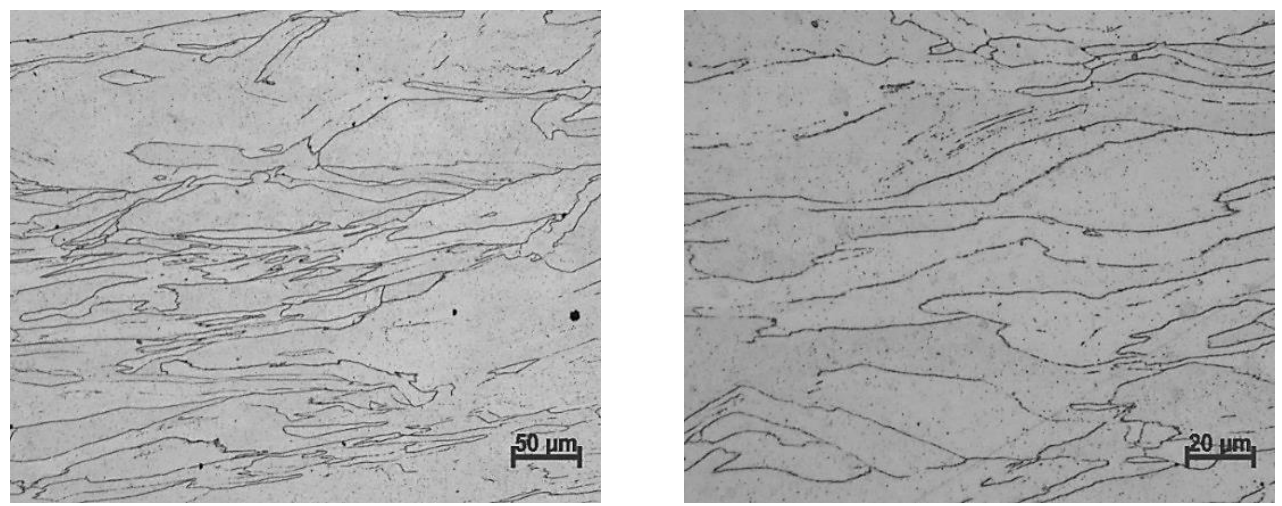

Fig. 6 Microstructure after rolling with $\varepsilon=71 \%$ under ambient temperature

\section{Conclusions}

1. The strength properties after the rolling under AT and CT conditions were significantly increased.

2. Initial properties after L-PBF + HT2 were: $R_{\mathrm{p} 0,2, \mathrm{AT}}=377 \mathrm{MPa}, \mathrm{R}_{\mathrm{m}}=552 \mathrm{MPa}$ and $\mathrm{A}_{\mathrm{t}}=$ $76,5 \%$ and $\mathrm{R}_{\mathrm{p} 0,2, \mathrm{CT}}=616 \mathrm{MPa}, \mathrm{R}_{\mathrm{m}, \mathrm{CT}}=1058 \mathrm{MPa}$ and $\mathrm{A}_{\mathrm{t}, \mathrm{CT}}=61,5 \%$.

3. The best level of yield strength was achieved after application of following conditions:

- HT2 + ambient rolling (298K) with deformation $\varepsilon=71 \%$ and tested by static tensile test at $298 \mathrm{~K}$ formed $\mathrm{R}_{\mathrm{p} 0,2}=1070 \mathrm{MPa}, \mathrm{R}_{\mathrm{m}}=1190 \mathrm{MPa}$ and $\mathrm{A}_{\mathrm{t}}=4,9 \%$

- $\mathrm{HT} 2+$ cryogenic rolling $(77 \mathrm{~K})$ with deformation $\varepsilon=40 \%$ and tested by static tensile test at $77 \mathrm{~K}$ formed $\mathrm{R}_{\mathrm{P} 0,2}=1390 \mathrm{MPa}, \mathrm{R}_{\mathrm{m}}=1580 \mathrm{MPa}$ and $\mathrm{A}_{\mathrm{t}}=7,5 \%$.

\section{References}

[1] A. Adeyemi, E.T. Akinlabi, R.M. Mahamood: Materials Today: Proceedings, Vol. 5, 2018, No. 9, p. 18510 - 18517, http://dx.doi.org/10.1016/j.matpr.2018.06.193

[2] H. Wu et al.: Ceramics International, Vol. 42, 2016, No. 15, p. 17290-17294, http://dx.doi.org/10.1016/j.ceramint.2016.08.024

[3] R. Rajesh, S.S. Sajjan, V. Kulkarni: International Journal of Current Engineering and scientific Research, Vol. 2, 2015, No. 10, p. 91-100

[4] T.G. Spears, S.A. Gold: Integrating Materials and Manufacturing Innovation, Vol. 5, 2016, No. 2, p. 1-25, http://dx.doi.org/10.1186/s40192-016-0045-4

[5] J.P. Kruth: Annals of the CIRP, Vol. 45, 1996, No. 1, p. 183-186, http://dx.doi.org/10.1016/S0007-8506(07)63043-1

[6] K.J.A. Brookes: Metal Powder Report, Vol. 70, 2015, No. 3, p. 137-140

[7] A.T. Sutton, C.S. Kriewall, M.C. Leu, J.W. Newkirk: Virtual and Psysical Prototyping, Vol.12, 2017, No. 1, p. 3-29, http://dx.doi.org/10.1080/17452759.2016.1250605

[8] D. Manfredi, R. Bidulsky: Acta Metallurgica Slovaca, Vol. 23, 2017, No. 3, p. 276-282, http://dx.doi.org/10.12776/ams.v23i3.988

[9] P. Petroušek et al.: MM Science Journal, Vol. 2017, 2017, p. 1752, http://dx.doi.org/10.17973/MMSJ.2017_02_2016190

[10] A. Fedorikova et al.: MM Science Journal, Vol. 2016, 2016, p. 1586, http://dx.doi.org/10.17973/MMSJ.2016_12_2016189 
[11] J. Bidulská, T. Kvačkaj, R. Bidulský, M.A. Grande, L. Lityńska-Dobrzyńska, J. Dutkiewicz, Chemicke Listy, Vol. 105, 2011, No. 16, p. 471-473

[12] J. Bidulská, T. Kvačkaj, I. Pokorný, R. Bidulský, M. Actis Grande: Archives of Metallurgy and Materials, Vol. 58, 2013, No. 2, p. 371-375, http://dx.doi.org/10.2478/amm-2013-0002

[13] M. Zavala-Arredondo et al: Materials and Design, Vol. 182, 2019, p. 108018, http://dx.doi.org/10.1016/j.matdes.2019.108018

[14]C. Zitelli, P. Folgarait, A. Di Schino: Metals, Vol. 9, 2019, No. 7, p. 731, http://dx.doi.org/10.3390/met9070731

[15]W.S.W. Harun: Powder Technology, Vol. 331, 2018, p. 74-97, http://dx.doi.org/10.1016/j.powtec.2018.03.010

[16] Ch. Yan et al: Materials Science and Engineering: A, Vol. 628, 2015, p. 238-246, http://dx.doi.org/doi.org/10.1016/j.msea.2015.01.063

[17] T. Neindorf et al: Metallurgical And Materials Transactions B, Vol. 44, 2013, No. 4, p. 794796, http://dx.doi.org/0.1007/s11663-013-9875-z

[18] I. Yadroitsev, I. Smurov: Psysics Procedia, Vol. 5, 2010, No. B, p. 551-560, http://dx.doi.org/10.1016/j.phpro.2010.08.083

[19] X. Wang, X. Gong, K. Chou: Procedia Manufacturing, Vol. 1, 2015, p. 287-295, http://dx.doi.org/10.1016/j.promfg.2015.09.026

[20] T. Vilaro et al: Metallurgical And Materials Transactions A, Vol. 42, 2011, No. 10, p. 31903199, http://dx.doi.org/0.1007/s11661-011-0731-y

[21] C.Y. Yap et al: Applied Physics Reviews, Vol. 2, 2015, No. 4, p. 041101, http://dx.doi.org/10.1063/1.4935926

[22] O. Di Pietro, O. Rufini, A. Di Schino: Acta Metallurgica Slovaca, Vol. 24, 2018, No. 3, p. 207-212, http://dx.doi.org/10.12776/ams.v24i3.1130

[23]A. Di Schino: Metallurgist, Vol. 61, 2017, No. 7-8, p. 549-557, http://dx.doi.org/10.1007/s11015-017-0531-8

[24]A. Di Schino, M. Richetta: Acta Metallurgica Slovaca, Vol. 23, 2017, No. 2, p. 111-121, http://dx.doi.org/10.12776/ams.v23i2.841

[25] Y. Xiong et al: Materials Science and Engineering A, Vol. 709, 2018, p. 270-276, http://dx.doi.org/10.1016/j.msea.2017.10.067

[26] B. Fu et al: Journal of Materials Science and Technology, Vol. 34, 2018, No. 4, p. 695-699, http://dx.doi.org/10.1016/j.jmst.2017.09.017

[27]D. Šimčák, T. Kvačkaj, R. Kočiško, R. Bidulský, J. Kepič, V. Puchý: Acta Metallurgica Slovaca, Vol. 23, 2017, No. 2, p. 99-104, http://dx.doi.org/10.12776/ams.v23i2.928

[28]R. Kumar et al: Materials and Design, Vol. 67, 2015, p. 637-643, http://dx.doi.org/doi.org/10.1016/j.matdes.2014.11.014

[29] Y. Guo et al: Journal of Materials Science and Technology, Vol. 31, 2015, No. 4, p. 403-412, http://dx.doi.org/10.1016/j.jmst.2014.08.014

[30]G. Kalinin et al: Journal of Nuclear Materials, Vol. 233-237, 1996, No. 1, p. 9-16, http://dx.doi.org/10.1016/S0022-3115(96)00316-9

[31] J. Qin et al: Cryogenics, Vol. 53, 2012, No. 7-9, p. 336-339

[32]H.J. Liu et al: Cryogenics, Vol. 51, 2011, No. 6, p. 234-236, http://dx.doi.org/10.4028/www.scientific.net/MSF.667-669.707

[33]T. Kvackaj et al: Acta Physica Polonica A, Vol. 126, 2014, No. 1, p. 184-186, http://dx.doi.org/10.12693/aphyspola.126.184 
[34]T. Kvačkaj et al: Acta Metallurgica Slovaca, Vol. 16, 2010, No. 4, p. 268-276

\section{Acknowledgements}

This work was supported by Slovak grant agency VEGA project No. 1/0599/18. 